\title{
Developmental Stage Is a Major Determinant of Lung Injury in a Murine Model of Bronchopulmonary Dysplasia
}

\author{
ERICA BÄCKSTRÖM, ANNA HOGMALM, URPO LAPPALAINEN, AND KRISTINA BRY
}

Department of Pediatrics, University of Gothenburg, 41685 Gothenburg, Sweden

\begin{abstract}
Bronchopulmonary dysplasia (BPD) is a common inflammatory lung disease in premature infants. To study the hypothesis that the sensitivity of the lung to inflammatory injury depends on the developmental stage, we studied postnatal lung development in transgenic mice expressing human IL-1 $\beta$ (hIL-1 $\beta$ ) in the lungs during the late canalicular-early saccular, saccular, or late saccularalveolar stage. Overexpression of hIL- $1 \beta$ in the saccular stage caused arrest in alveolar development, airway remodeling, and goblet cell hyperplasia in the lungs as well as poor growth and survival of infant mice. Overexpression of hIL- $1 \beta$ during the late canalicular-early saccular stage did not adversely affect lung development, growth, or survival of the pups. Mice expressing hIL-1 $\beta$ from the late saccular to alveolar stage had smaller alveolar chord length, thinner septal walls, less airway remodeling and mucus metaplasia, and better survival than mice expressing hIL- $1 \beta$ during the saccular stage. Human IL-1 $\beta$ overexpression in the saccular stage was sufficient to cause a BPD-like illness in infant mice, whereas the lung was more resistant to hIL-1 $\beta$-induced injury at earlier and later developmental stages. (Pediatr Res 69: 312-318, 2011)
\end{abstract}

$\mathrm{B}$ ronchopulmonary dysplasia (BPD), the major chronic lung disease in children, is an important cause of longterm morbidity, poor growth, and mortality in premature infants (1). Lung pathology in BPD shows inflammation and abnormal alveolar and vascular development (2).

The mammalian lung undergoes five distinct developmental stages: the embryonic [3-7 gestational weeks (GW) in the human and embryonic day (E) 9-11.5 in the mouse], pseudoglandular (5-17 GW in the human and E11.5-16.5 in the mouse), canalicular (16-26 GW in the human and E16-18 in the mouse), saccular (24-38 GW in the human and E17.5postatnal day (PN) 5 in the mouse), and alveolar (from $\sim 36$ GW in the human and PN5-28 in the mouse) stages. Children developing BPD are typically born at 23-29 GW, i.e. during the early saccular stage, whereas BPD is rare in infants born during the late saccular to alveolar stage, i.e. at GA $>30 \mathrm{wk}$ (1).

Inflammation, a cardinal feature of BPD, can be induced in the preterm lung by various pre and postnatal insults. The majority of premature infants born between 23 and $29 \mathrm{GW}$ are exposed to chorioamnionitis (3). In some pregnancies, in-

Received June 17, 2010; accepted November 1, 2010.

Correspondence: Kristina Bry, M.D., Ph.D., Department of Pediatrics, University of Gothenburg, The Queen Silvia Children's Hospital, SWE-416 85 Gothenburg, Sweden; e-mail: kristina.bry@pediat.gu.se

Supported by the Swedish Medical Research Council, the Swedish Heart and Lung Foundation, the Frimurare Barnhus Foundation, the Swedish Government Grants for Medical Research [K.B.]. In addition, E.B. received funding from the Queen Silvia Children's Hospital Research Foundation. creased levels of inflammatory cytokines are present in amniotic fluid already during the canalicular stage of lung development (3). Postnatal therapies such as ventilation and administration of supplemental oxygen also promote inflammation in the lung (1).

Increased concentration of the central inflammatory cytokine IL- $1 \beta$ in amniotic fluid or postnatally in the lungs of newborn infants is associated with the development of BPD $(4,5)$. Using a bitransgenic mouse in which expression of human (h) IL- $1 \beta$ is induced in the lung by doxycycline (dox) administration (6), we have shown that overexpression of hIL- $1 \beta$ in the lung from the pseudoglandular to the alveolar stages causes a lung disease similar to BPD, characterized by lung inflammation, arrest in alveolar development, airway remodeling, poor postnatal growth, and increased mortality in infant mice (7).

To study the hypothesis that the vulnerability of the lung to an inflammatory injury is dependent of the stage of lung development, we studied postnatal lung development in infant mice in whose lungs the overexpression of hIL- $1 \beta$ was induced during the different developmental stages. The present results show that production of hIL- $1 \beta$ in the saccular stage causes a BPD-like illness in infant mice.

\section{MATERIALS AND METHODS}

Conditional expression of hIL-1ß in the mouse lung. Bitransgenic mice with dox-inducible expression of mature hIL-1 $\beta$ were generated as previously described (6). Single-transgenic littermates lacking the hIL-1 $\beta$ transgene were used as controls to study specifically the effects of hIL-1 $\beta$ expression on the lung phenotype (8). All mice were genotyped by PCR analysis of genomic tail DNA using primers specific for transgene constructs as described (6).

Animal care. The experiments were approved by the Institutional Animal Care and Use Committee at the University of Gothenburg. The mice were housed in pathogen-free conditions and had free access to water and laboratory chow. The vaginal plug date was counted as E0. The date of birth was counted as PNO. Before sample collection, the animals were anesthetized by i.p. injection of a mixture of ketamine, xylazine, and acepromazine and exsanguinated by transection of abdominal vessels.

Administration of dox. To induce hIL-1 $\beta$ expression antenatally and postnatally in bitransgenic offspring, pregnant dams received dox (Sigma Chemical Co., St. Louis, MO) at a dose of $0.5 \mathrm{mg} / \mathrm{mL}$ in drinking water at E15-16.5 (36 h), at E17.5-PN0 (36 h), or from E0 until sacrifice of the pups on PN7. Dox administration induces hIL-1 $\beta$ overexpression in bitransgenic offspring starting at E14 (7). The dox solution was protected from light by covering cage bottles with aluminum foil and changed three times per week. To initiate hIL- $1 \beta$ expression in the lungs of bitransgenic pups after birth, dox

Abbreviations: Areg, amphiregulin; BPD, bronchopulmonary dysplasia; dox, doxycycline; E, embryonic day; GW, gestational weeks; hIL-1 $\boldsymbol{\beta}$, human interleukin-1 $\beta$; PAS, Periodic acid Schiff; PN, postnatal day 
(Merckle GmbH, Blaubeuren, Germany) was administered by three i.p. injections at a dose of $0.15 \mathrm{mg} /$ injection at PN0, PN0.5, and PN1.

RNA isolation and quantitative RT-PCR. Total RNA from lung tissue was isolated, reverse transcribed, and analyzed by real-time PCR as described (7). Intron-spanning primers, gene-specific for amphiregulin (Areg), monocyte chemoattractant protein-1 (MCP-1, CCL2), keratinocyte chemokine (KC, the mouse homologue of human CXC chemokine growth-related oncogene- $\alpha$, CXCL1), Ym1 (Chitinase 3-like 3), and Ym2 (Chitinase 3-like 4) were used for the quantification of mRNA levels. Primer sequences (forward and reverse, respectively, $5^{\prime}$ to $3^{\prime}$ ) for Areg were TGC TGT TGC TGC TGG TCT TAG GCT; GAA GGC ATT TCG CTT ATG TGT GAA. For the other primer sequences, see Bäckström et al. (9).

Human IL-1ß, chemokine, and total protein measurement in lung homogenates. Fetal and postnatal lung tissue was homogenized and centrifuged, and the concentrations of hIL-1 $\beta$ and chemokines were measured in the supernatant (7). DuoSet ELISA development kits (R\&D Systems, Abingdon, UK) were used to quantify hIL- $1 \beta$ (with no cross-reactivity with murine IL-1 $\beta$ ) and mouse chemokines CXCL1 and CCL2. Assay standard concentration ranges were $3.9-250 \mathrm{pg} / \mathrm{mL}$ (hIL-1 $\beta$, CCL2) and $15.6-1000 \mathrm{pg} / \mathrm{mL}$ (CXCL1). Total protein concentration was measured using the bicinchoninic acid method (Sigma Chemical Co.) (7).

Lung histology and immunohistochemistry. Lungs were inflation-fixed (at PN7 and PN12) and paraffin-embedded as described (6). Five-micrometer tissue sections were stained with hematoxylin and eosin or Alcian blue/ Periodic acid Schiff (PAS) (pH 2.5) and counterstained with Mayer's hematoxylin (7). Immunohistochemical staining for neutrophils, macrophages, and the proliferation marker Ki-67 was performed using monoclonal rat antimouse neutrophil, clone 7/4 (1:50; Serotec, Oxford, UK), monoclonal rat anti-mouse Mac3, clone M3/84 (1:50; BD Biosciences Pharmingen, San Diego, CA), and polyclonal rabbit anti-human (cross-reacts with mouse) Ki-67 antibodies as described (1:500; Novocastra Laboratories Ltd. Newcastle-upon-Tyne, UK) $(9,10)$. In situ DNA nick-end labeling (TUNEL) for detection of apoptotic cells was performed as described (11).

Quantification of positively stained cells. The numbers positively stained cells were counted in 10 random high-power fields $(40 \times$ lens for neutrophils, macrophages, and TUNEL and $100 \times$ lens for $\mathrm{Ki}-67)$ in each section ( $\geq$ four animals per group), and the average numbers of positive cells per square millimeter were calculated (9). The percentage of goblet cells was assessed on Alcian blue/PAS stained lung tissue section as described (9).

Statistics. Data are expressed as mean \pm SEM. Groups were compared with Student's two-tailed unpaired $t$ test. ANOVA with Bonferroni post hoc test was used when more than two groups were compared. Neonatal mortality data were analyzed using Kaplan-Meier survival analysis and logrank (Mantel-Cox) test. The $p$ values $<0.05$ were considered statistically significant.

\section{RESULTS}

Production of hIL-1及 in the fetal and newborn lung. Administration of dox at E15-16.5 resulted in a peak of hIL-1 $\beta$ production during E16-18.5, i.e. during the late canalicular-early saccular stage, whereas dox treatment at E17.5-

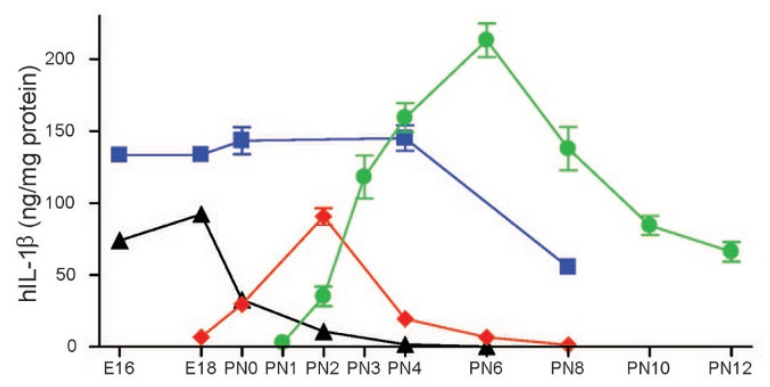

Figure 1. Production of hIL-1 $\beta$ in the lungs of fetuses and newborns. Dox treatment at E15-16.5 (black) or E17.5-PN0 (red) resulted in a peak of hIL-1 $\beta$ production in the late canalicular to the early saccular stage and the saccular stage, respectively, whereas dox treatment at E0-PN7 (blue) induced hIL-1 $\beta$ production from the pseudoglandular to the alveolar stage. Postnatal dox (green) resulted in a wide peak of hIL- $1 \beta$ production culminating during the alveolar stage. $n \geq 4$ in each group.
PN0 resulted in maximal hIL-1 $\beta$ production during PNO-3, i.e. during the mid-saccular stage (Fig. 1). The peak concentrations of hIL- $1 \beta$ in the lungs were similar in the two $36-\mathrm{h}$ treatment groups, $\sim 90 \mathrm{ng}$ hIL-1 $\beta / \mathrm{mg}$ protein. Dox treatment from E0 until PN7 caused hIL-1 $\beta$ production from E14 to PN7, i.e. from the pseudoglandular to the alveolar stage. The levels of hIL- $1 \beta$ resulting from dox treatment from E0 to PN7 reached a plateau at $\sim 140 \mathrm{ng}$ hIL- $1 \beta / \mathrm{mg}$ protein at E16 and remained approximately at this level until PN4. Postnatally, from PN4 to PN8, the hIL- $1 \beta$ production decreased by $60 \%$ (Fig. 1), probably owing to low concentrations of dox in milk and poor enteral absorption of dox in the presence of milk.

To initiate hIL- $1 \beta$ production postnatally, dox was administered by i.p. injections ( $0.15 \mathrm{mg} /$ injection) at PNO, PN0.5, and PN1 because postnatal administration of dox in drinking water $(1 \mathrm{mg} / \mathrm{mL})$ and/or food pellets $(1.25 \mathrm{mg} / \mathrm{g})$ to nursing dams resulted in very low levels of hIL- $1 \beta$ production in the lungs of bitransgenic pups (data not shown). Dox injections resulted in hIL-1 $\beta$ production in the lungs of bitransgenic pups from PN 2 to 12, i.e. from the late saccular to the alveolar
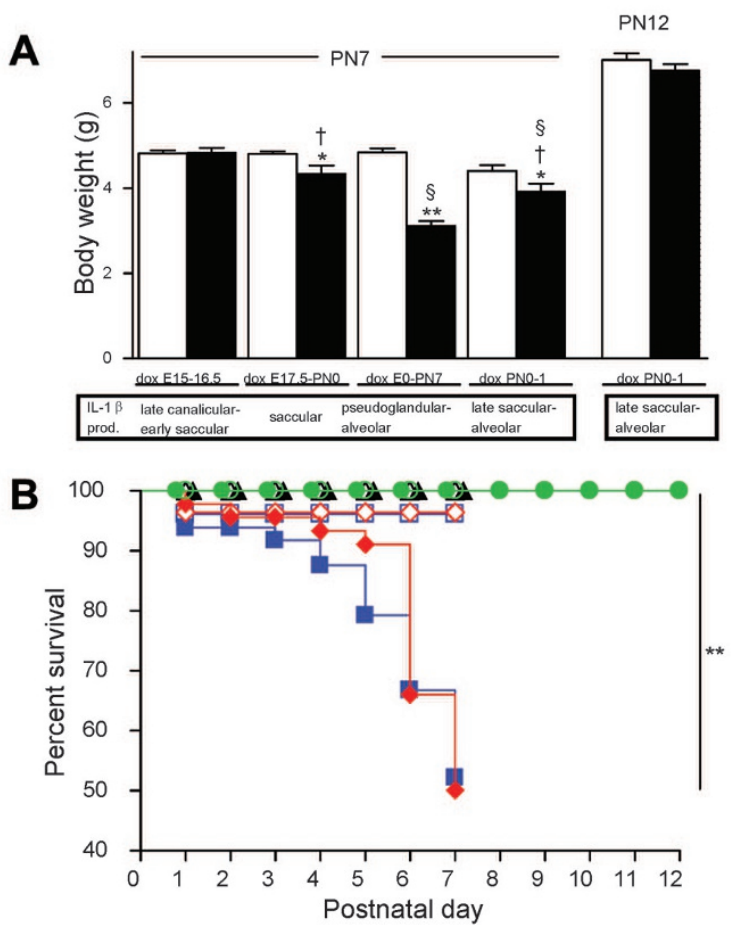

Figure 2. Time of hIL-1 $\beta$ overexpression affected postnatal growth and survival. (A) Weight of pups at PN7 and PN12. Bitransgenic pups given dox at E17.5-PN0, E0-PN7, or PN0-1 weighed less than controls at PN7. The weight difference between control and bitransgenic pups given dox at PN0-1 was no longer significant at PN12. Open bars: control (ctrl) pups, black bars: bitransgenic (bi-TG) pups. $n \geq 15$ in each group. * $p \leq 0.05$ and $* * p \leq$ 0.001 , bi-TG pups compared with ctrl pups within treatment group; $\S p \leq$ 0.01 , compared with bi-TG pups given dox at E15-16.5; and $\dagger p \leq 0.01$, compared with bi-TG pups given dox at E0-PN7. (B) Survival until PN7 and PN12. Dox treatment at E17.5-PN0 or E0-PN7 decreased the survival of bitransgenic pups, whereas dox given at E15-16.5 or at PN0-1 did not affect survival of bitransgenic pups. $* * p \leq 0.001$, bitransgenic pups given dox at E0-PN7 or E17.5-PN0 compared with all other groups, $n \geq 15-55$ in each group. Dox E15-16.5 (black): $\triangle$, ctrl pups; $\Delta$-bi-TG pups. Dox E17.5-PN0 (red): $\diamond$, ctrl pups; $\diamond$, TG pups. Dox E0-PN7 (blue): $\square$, ctrl pups; $\mathbf{\square}$, bi-TG pups, Dox PN0-1 (green): $\bigcirc$, ctrl pups; $\bullet$, bi-TG pups. 


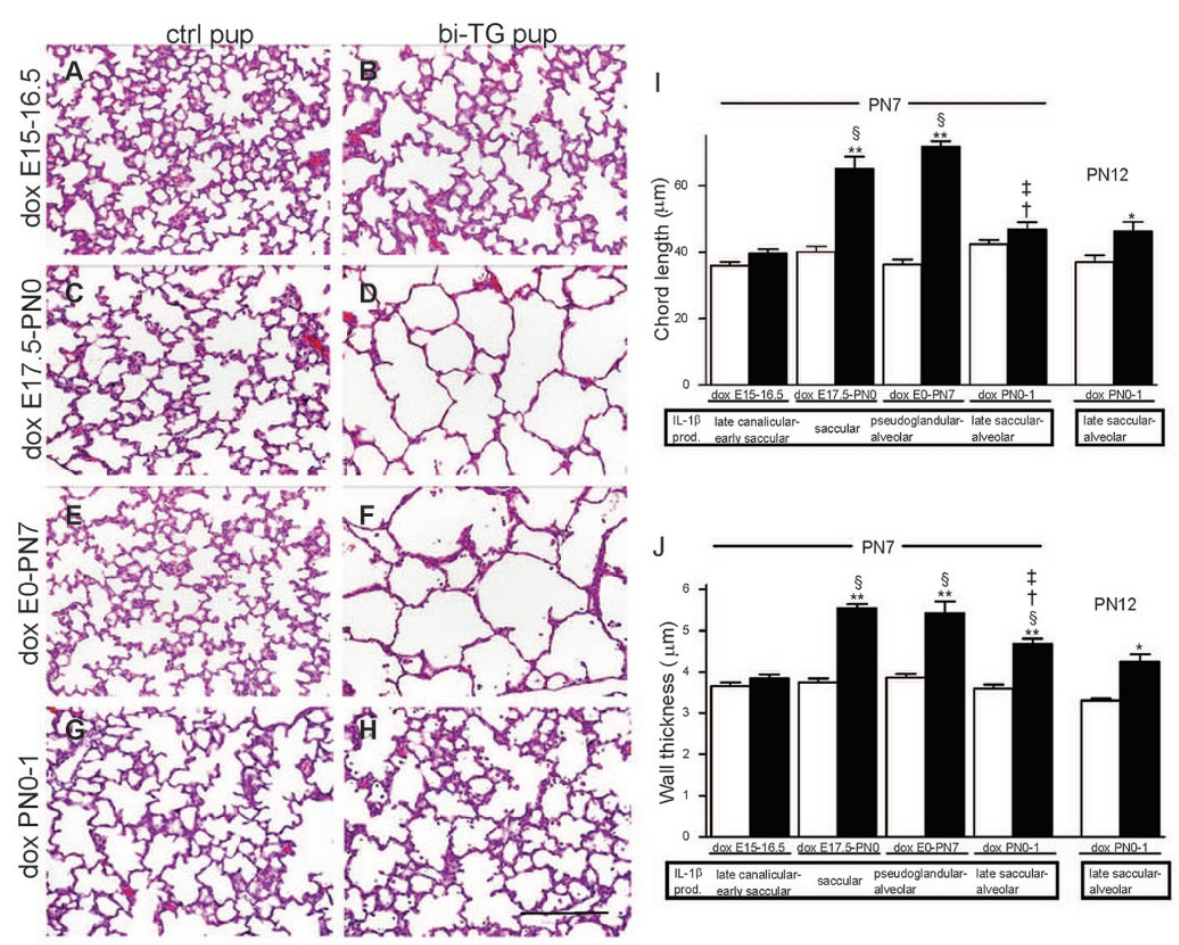

Figure 3. Time of hIL-1 $\beta$ expression affects alveolar development. (A-H) Lung histology at PN7. (I) Alveolar chord length. Dox treatment at E17.5-PN0 or E0-PN7 severely inhibited alveolar septation $(D, F, I)$. At PN12, alveolar chord length was slightly greater in bitransgenic pups than in controls given dox at PNO-1 $(I)$. $(J)$ Septal wall thickness. Open bars: ctrl pups, black bars: bi-TG pups. $n \geq 5$ in each group. Scale bar: $200 \mu \mathrm{m}$. * $p \leq 0.05$ and $* * p \leq$ 0.001 , bi-TG pups compared with ctrl pups within treatment group; $\S p \leq 0.05$, compared with bi-TG pups given dox at E15-16.5; † $p \leq$ 0.05 , compared with bi-TG pups given dox at E0-PN7; and $\$ p \leq 0.01$, compared with bi-TG pups given dox at E17.5-PN0. stage. The maximal level of $\sim 210 \mathrm{ng}$ hIL-1 $\beta / \mathrm{mg}$ protein was reached at PN6 (Fig. 1).

Dependence of postnatal growth and mortality of newborn mice on timing of hIL-1及 overexpression. The birth weights of hIL-1 $\beta$-expressing pups and their control littermates did not differ (data not shown). At PN7, the weights of bitransgenic pups and controls given dox at E15-16.5 were similar (Fig. $2 A)$. In contrast, postnatal growth was poorer in bitransgenic pups compared with controls when dox was administered at E17.5-PN0, at E0-PN7, or at PN0-1 (Fig. 2A). Because the peak of hIL-1 $\beta$ production occurred later in bitransgenic pups given dox at PN0-1 than in the other groups, mice treated with dox at PN0-1 were studied at PN12 in addition to PN7. Bitransgenic pups given dox at PN0-1 weighed less than their controls at PN7, but not at PN12, indicating catch-up growth in this group of bitransgenic mice (Fig. 2A).

Except for a few deaths in the immediate postnatal period, all control littermates in all the treatment groups survived until PN7 (Fig. 2B). Survival at PN7 was 100\% among bitransgenic pups given dox at E15-16.5. Similarly, all bitransgenic pups given dox at PN0-1 survived until PN12 (Fig. 2B). In contrast, dox administration at E17.5-PN0 or E0-PN7 decreased the survival of bitransgenic pups by $\sim 50 \%$ (Fig. $2 B$ ). Because of very high mortality after PN7, bitransgenic pups given dox at E17.5-PN0 or at E0-PN7 could not be studied at PN12.

Overexpression of $h I L-1 \beta$ during the saccular stage caused arrest in alveolar development. Alveolar septation was progressing at PN7 in all the control groups and in the bitransgenic pups given dox at E15-16.5 or PN0-1 (Fig. $3 A-C, E, G$, and $H$ ). In contrast, hIL- $1 \beta$ expression during the saccular stage (dox E17.5-PN0) or from the pseudoglandular through the alveolar stage (dox E0-PN7) disrupted alveolar septation (Fig. 3D and $F$ ). The mean alveolar chord length was significantly greater in these two groups of bitransgenic pups than in their controls and in the two other groups of bitransgenic pups (Fig. 3I). Interestingly, hIL-1 $\beta$ overexpression during the saccular stage was sufficient to disrupt alveolar septation to a similar degree as hIL- $1 \beta$ expression from the pseudoglandular through the alveolar stage (Fig. 3I). Although the alveolar chord length of bitransgenic pups given dox at PN0-1 did not differ from that of controls at PN7 (Fig. 3I), they had a greater alveolar chord length than their controls at PN12, indicating that hIL-1 $\beta$ overexpression during the alveolar stage inhibited alveolar septation, albeit to a lesser degree than hIL-1 $\beta$ expression during the saccular stage (Fig. 3I). The $16 \%$ difference in chord lengths between bitransgenic and control pups given dox at PN0-1 at PN12 was much smaller than the chord length difference at PN7 between bitransgenic and control pups in the groups given dox at E17.5-PNO $(38 \%)$ or at E0-PN7 (50\%).

Human IL- $1 \beta$ expression during the late canalicular to early saccular stage did not affect alveolar wall thickness (Fig. 3J). Expression of hIL- $1 \beta$ in the other groups of bitransgenic mice prevented alveolar wall thinning (Fig. 3J). However, alveolar walls were thinner in bitransgenic pups given dox at PN0-1 than in those given dox at E17.5-PN0 or at E0-PN7 (Fig. 3J). The difference of $23 \%$ in alveolar wall thickness at PN7 between bitransgenic pups and their control littermates given dox at PN0-1 remained similar at PN12 (Fig. 3J).

Neutrophil and macrophage infiltration in the alveolar regions of the lungs of mice expressing hIL-1ß. Dox treatment at E17.5-PN0, E0-PN7, or PN0-1, but not at E15-16.5, caused infiltration of the lungs of bitransgenic pups with neutrophils and macrophages at PN7 (Fig. 4). Neutrophil and macrophage infiltration was greater in hIL- $1 \beta$ producing pups given dox at E0-PN7 or at PN0-1 than in those given dox at 

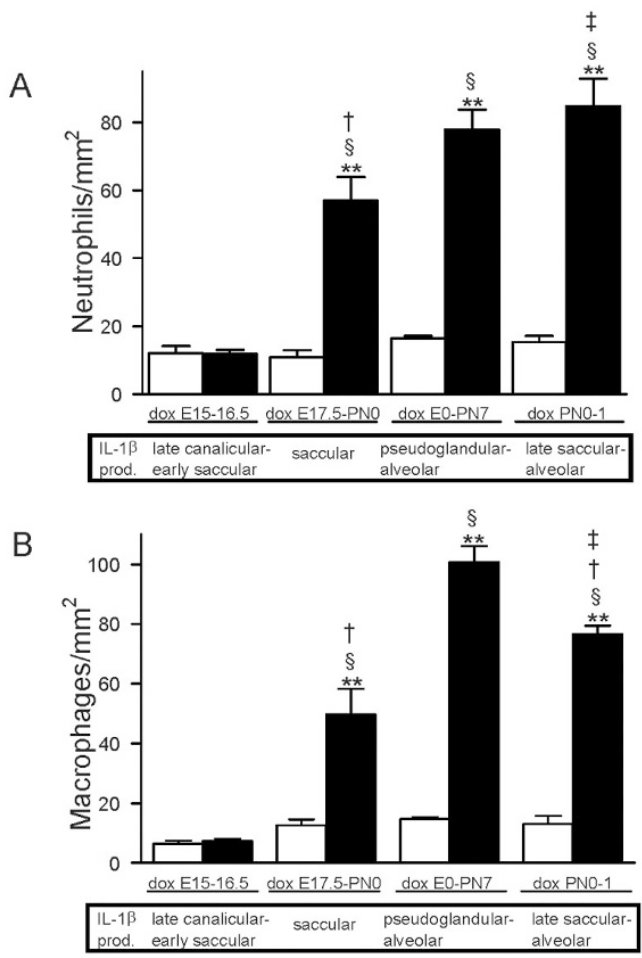

Figure 4. Inflammatory cells in the lungs at PN7. (A) Neutrophil count. (B) Macrophage count. Dox treatment at E17.5-PN0, E0-PN7, or PN0-1 caused infiltration of the lungs of bitransgenic pups with neutrophils and macrophages. Open bars: ctrl pups, black bars: bi-TG pups. $n \geq 4$ in each group. $* * p \leq 0.001$, bi-TG pups compared with ctrl pups within treatment group; $\$$ $p \leq 0.001$, compared with bi-TG pups given dox at E15-16.5; $\dagger p \leq 0.05$, compared with bi-TG pups given dox at E0-PN7; and $\ddagger p \leq 0.05$, compared with bi-TG pups given dox at E17.5-PN0.

E17.5-PN0 (Fig. 4A). In the lungs of bitransgenic mice given dox at PN0-1, neutrophil and macrophage infiltration persisted at the same level at least until PN12 (neutrophils $/ \mathrm{mm}^{2}$ : control pups $11.7 \pm 1.4$, bitransgenic pups $79.8 \pm 12.2, p \leq$ 0.001 ; macrophages $/ \mathrm{mm}^{2}$ : control pups $18.1 \pm 1.9$, bitransgenic pups $91.6 \pm 13.0, p \leq 0.001$ ).
Dox administration at E17.5-PN0, E0-PN7, or PN0-1 increased the mRNA expression and protein production of the neutrophil chemokine CXCL1 and of the macrophage chemokine CCL2 compared with controls (Fig. 5A-D). Thus, as expected, the levels of CXCL1 and CCL2 paralleled the numbers of neutrophils and macrophages in the lungs.

The timing of hIL-1及 overexpression influenced airway remodeling and the expression of $\mathrm{Ym} 1, \mathrm{Ym} 2$, and amphiregulin in the lungs of infant mice. Airway structure at PN7 was similar in all groups of control pups (Fig. 6A, $C, E$, and $G$ ) and in bitransgenic infant mice given dox at E15-16.5 or at PN0-1 (Fig. $6 B$ and $H$ ). Inflammatory cells accumulated in and around the airways of hIL- $1 \beta$-expressing offspring given dox at E0-PN7 or at E17.5-PN0 (Fig. $6 D$ and $F$ ). In addition, the airways of these groups of bitransgenic mice were thicker and had more goblet cell hyperplasia than those of control mice and of the other two bitransgenic groups (Fig. 6A-H). The distribution of airways having different percentages of PAS-positive goblet cells $(<10 \%, 11-40 \%, 41-80 \%$, or $>81 \%$ ) was studied (Fig. 6 I). The majority of the airways in all the control groups and in the bitransgenic group given dox at E15-16.5 had $<10 \%$ goblet cells and none had $>81 \%$. Approximately $60 \%$ of the airways in bitransgenic pups given dox at E17.5-PN0 or at E0-PN7 had $>81 \%$ goblet cells and $\sim 20 \%$ of their airways had $41-80 \%$ goblet cells. In contrast, bitransgenic pups given dox PNO-1 had $>81 \%$ goblet cells in only $6 \%$ of their airways, whereas the majority of their airways (88\%) had $<10 \%$ goblet cells at PN7 (Fig. 6I). The distribution remained similar until PN12, at which time $8 \%$ of the airways had $>81 \%$ goblet cells and the majority $(83 \%)$ had $<10 \%$ goblet cells.

Dox administration at E15-16.5 did not modify the expression of the chitinase-like lectins $\mathrm{Ym} 1$ and $\mathrm{Ym} 2$ in the lungs of bitransgenic pups at PN7 (Fig. $6 J$ and $K$ ). Ym1 and Ym2 expression was strongly up-regulated in bitransgenic pups given dox at E17.5-PN0 or E0-PN7, whereas only a modest increase in the expression of the lectins was present in bitrans-
A

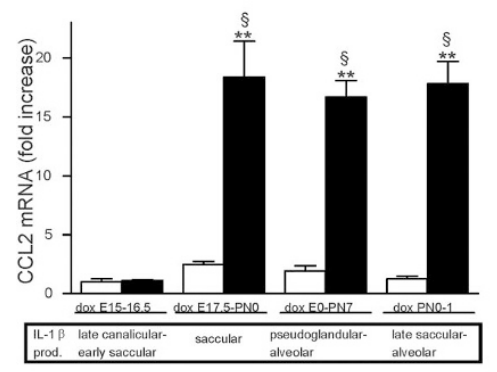

C

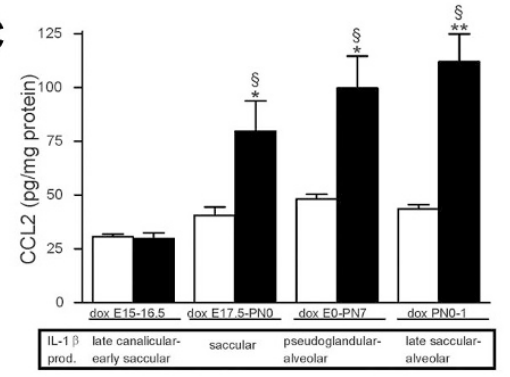

B

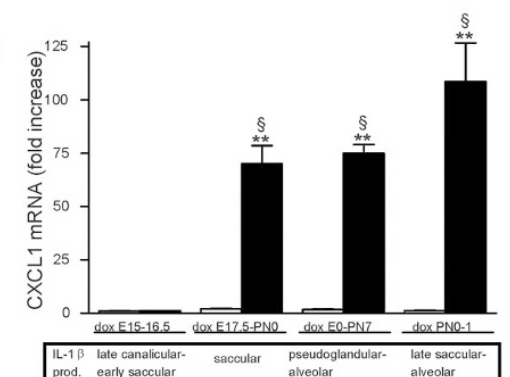

D

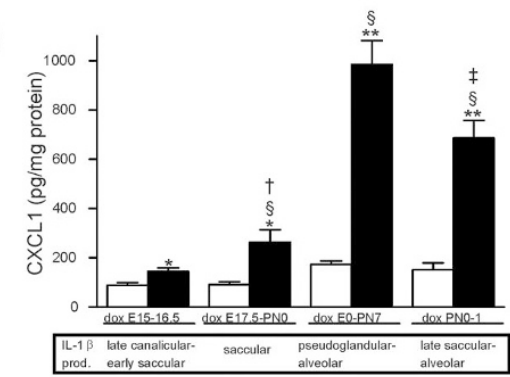

Figure 5. Expression and production of CCL2 and CXCL1 in the lungs of infant mice at PN7. $(A, B)$ Expression of CCL2 and CXCL1. $(C, D)$ Production of CCL2 and CXCL1. Open bars: ctrl pups, black bars: bi-TG pups. $n \geq 4$ in each group. $* p \leq 0.05$ and $* * p \leq 0.001$, bi-TG pups compared with ctrl pups within treatment group; $\S p \leq 0.05$, compared with bi-TG pups given dox at E15-16.5; $\dagger p \leq 0.05$, compared with bi-TG pups given dox at E0-PN7; and $\ddagger p \leq$ 0.01 , compared with bi-TG pups given dox at E17.5-PN0. 

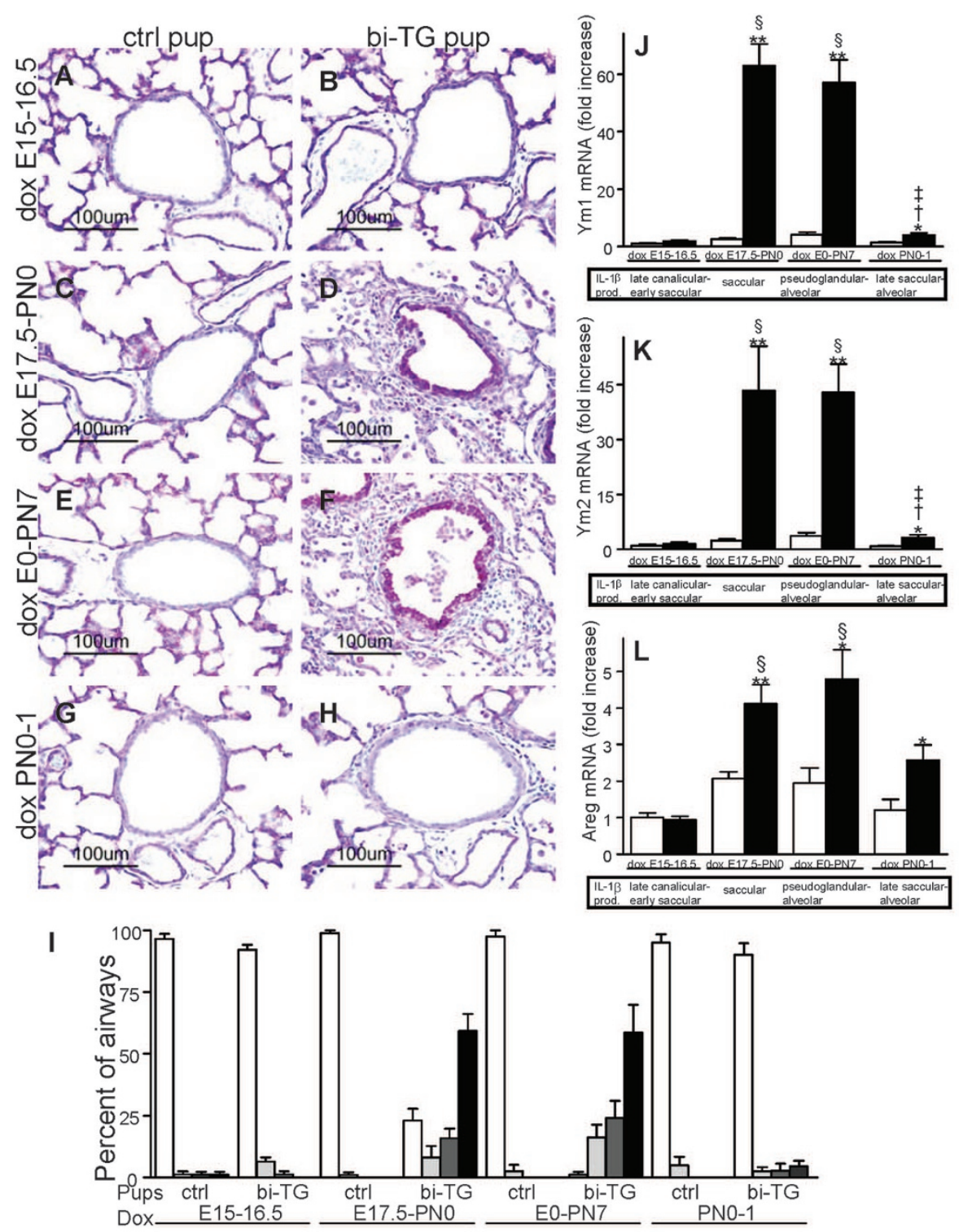

Figure 6. Airway remodeling, goblet cell hyperplasia, and expression of amphiregulin and chitinase-like lectins $\mathrm{Ym} 1$ and $\mathrm{Ym} 2$ in the lungs of infant mice at PN7. (A-H) Alcian blue/PAS stained lung tissue sections. Bitransgenic pups administered dox at E17.5-PN0 $(D)$ and E0-PN7 $(F)$ had thicker airway walls and more goblet cell hyperplasia than the other two groups of bitransgenic pups $(B, H)$. (I) Distribution (in \%) of airways with different proportions of goblet cells in the epithelium. Open bars, airways with $\leq 10 \%$ goblet cells; gray bars, airways with 11-40\% goblet cells; dark gray bars, airways with 41-80\% goblet cells; black bars, airways with $\geq 81 \%$ goblet cells. $(J-L) \mathrm{Ym} 1, \mathrm{Ym} 2$, and Areg expression. Open bars, ctrl pups; black bars, bi-TG pups. $n \geq 4$ in each group. $* p \leq$ 0.05 or $* * p \leq 0.001$, bi-TG pups compared with ctrl pups within treatment group; $\S p \leq$ 0.001 , compared with bi-TG pups given dox at E15-16.5; $\dagger p \leq 0.01$, compared with bi-TG pups given dox at E0-PN7; and $\ddagger p \leq 0.01$, compared with bi-TG pups given dox at E17.5-PN0. genic mice given dox at PN0-1. The expression of Areg was higher in all groups of hIL-1 $\beta$-expressing pups compared with their control groups, except in those given dox at E15-16.5 (Fig. 6L).

Apotosis and proliferation in the lungs of infant mice. Bitransgenic pups given dox at E17.5-PN0 or at E0-PN7 had increased numbers of apoptotic cells in the distal lung compared with their controls as well as compared with bitransgenic pups given dox at E15-16.5 (Fig. 7A). Dox administration at PNO-1 also enhanced apoptosis in the bitransgenic lungs at PN7. However, the number of apoptotic cells in bitransgenic pups given dox at PN0-1 was significantly smaller than the number of apoptotic cells in bitransgenic pups given dox at E0-PN7. In mice given dox at PN0-1, the difference between the numbers of apoptotic cells in the lungs of bitransgenic and control were no longer significant at PN12 (Fig. 7A). No significant differences were seen in the numbers of proliferating cells between control and bitransgenic pups in any treatment group (Fig. 7B).

\section{DISCUSSION}

We have previously shown that prolonged perinatal overexpression of hIL-1 $\beta$ in the lung epithelium causes a BPD-like illness in the infant mouse (7). This study demonstrates that hIL- $1 \beta$ production in the lung during the saccular stage of lung development is sufficient to similarly disrupt lung development in newborn mice. The lung disease was associated with poor postnatal growth and high mortality. During normal alveolarization, septation resulting in a sufficiently large alveolar surface area is accompanied by thinning of the alveolar/ septal walls to optimize gas exchange (12), whereas in infants with BPD, the distal airspaces remain large and the septal walls thick (13). Human IL-1 $\beta$ overexpression during the saccular stage arrested alveolar septation and prevented septal wall thinning. Similarly, Moss et al. (14) showed that intraamniotic administration of endotoxin to fetal lambs during the early canalicular stage reduced the number of alveoli in fetal lambs. Although hIL-1 $\beta$ production during the late saccular 


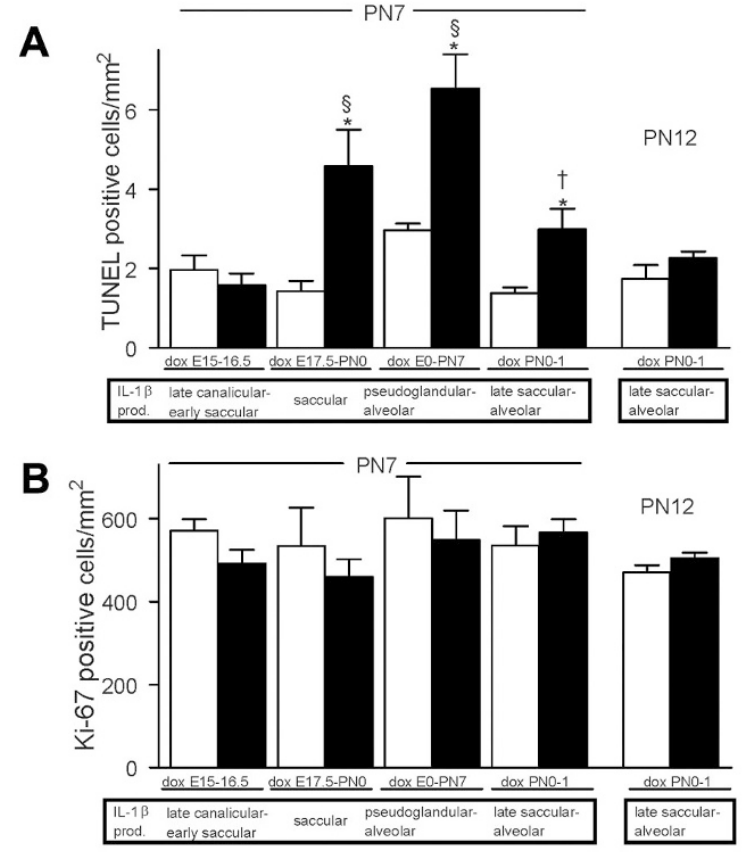

Figure 7. Apoptosis and proliferation. (A) The number of apoptotic (TUNEL positive) cells in the distal lung. $(B)$ The number of proliferating (Ki-67 positive) cells in the distal lung. Open bars, ctrl pups; black bars, bi-TG pups. $n \geq 4$ in each group. $* p \leq 0.05$, bi-TG pups compared with ctrl pups within treatment group; $\S p \leq 0.05$, compared with bi-TG pups given dox at E15-16.5; and $\dagger p \leq 0.01$, compared with bi-TG pups given dox at E0-PN7.

and alveolar stages caused pulmonary inflammation, it only resulted in a small increase in alveolar size and wall thickness, and did not decrease postnatal survival or permanently inhibit the growth of the pups. These results are consistent with clinical findings showing that the risk for severe BPD is highest in children born between 23 and $27 \mathrm{GW}$, i.e. during the early saccular stage of lung development, whereas it is low in children born after $32 \mathrm{wk}$ of gestation, i.e. in the late saccular-alveolar stage (1).

Neutrophils and macrophages accumulate in the lungs of newborn infants developing BPD (15). Overexpression of hIL-1 $\beta$ during the saccular or alveolar stages of lung development caused infiltration of the lung with neutrophils and macrophages. CC and CXC chemokines mediate monocyte and neutrophil recruitment, respectively. Increased tracheal aspirate concentrations of CCL2 and CXCL1 (IL-8) in newborn infants early in life are associated with the development of BPD $(16,17)$. In the lungs of mice expressing hIL-1 $\beta$ during different stages of development, the levels of CCL2 and CXCL1 paralleled the numbers of inflammatory cells. However, the severity of the lung disease in hIL-1 $\beta$ expressing mice was not directly related to the magnitude of the neutrophil or macrophage infiltration in the lung or the levels of chemokines, because the disruption of lung development was relatively modest in mice expressing hIL- $1 \beta$ during the alveolar stage despite their having a strong pulmonary inflammation and high levels of chemokines. These results suggest that the stage of lung development is a more important factor in the development of inflammatory lung injury than the magnitude of the inflammatory response.
Airway inflammation, thickening of the bronchial epithelium, and increased mucus production leading to lobar or segmental atelectasis are features of severe BPD (18). In our model, hIL- $1 \beta$ production during the saccular stage caused similar airway remodeling in the lungs of mice. Interestingly, mice expressing hIL- $1 \beta$ during the alveolar stage had less inflammation around the airways, less thickening of the airway epithelium, and less goblet cell hyperplasia than mice expressing hIL-1 $\beta$ during the saccular stage.

Chitinase-like lectins $\mathrm{Ym} 1$ and $\mathrm{Ym} 2$, abundantly expressed during the development of allergic airway disease, promote allergic airway inflammation (19). The human $\mathrm{Ym} 1$ and $\mathrm{Ym} 2$ homologue YKL-40 that has a proinflammatory role in chronic obstructive pulmonary disease (20) is linked to disease severity in asthmatics $(21,22)$. Overexpression of hIL-1 $\beta$ during the saccular stage caused a 40- to 60-fold increase in the expression of $\mathrm{Ym} 1$ and $\mathrm{Ym} 2$ in the lungs of infant mice, whereas hIL-1 $\beta$ overexpression during the alveolar stage caused only a minor increase in the expression of these lectins. No increase in Ym1 or Ym2 expression occurred after hIL-1 $\beta$ expression during the late canalicular to early saccular stage. Thus, the expression of $\mathrm{Ym} 1$ and $\mathrm{Ym} 2$ paralleled the severity of airway inflammation and remodeling in hIL-1 $\beta$-expressing mice. Areg, a member of the epidermal growth factor family, has been shown to up-regulate mucin gene expression in airway epithelial cells (23). In the present model, the expression of Areg, induced by hIL- $1 \beta$ expression during the saccular and alveolar stages, correlated with the severity of goblet cell hyperplasia in the airways.

Murine models such as the present transgenic model of neonatal inflammatory lung disease have limitations. However, the model makes it possible to study the influence of inflammation per se on lung development during the different developmental stages, independent of other variables (such as premature birth or variable pre- or postnatal clinical conditions or therapies).

The majority of premature infants are exposed to antenatal inflammation (3). In addition, postnatal therapies, such as oxygen administration and ventilation, cause inflammation in the lungs of these infants (1). The present results suggest that the stage of lung development is a primary factor that determines vulnerability to inflammatory lung injury.

\section{REFERENCES}

1. Jobe AH, Bancalari E 2001 Bronchopulmonary dysplasia. Am J Respir Crit Care Med 163:1723-1729

2. Coalson JJ 2003 Pathology of new bronchopulmonary dysplasia. Semin Neonatol 8:73-81

3. Goldenberg RL, Hauth JC, Andrews WW 2000 Intrauterine infection and preterm delivery. N Engl J Med 342:1500-1507

4. Yoon BH, Romero R, Jun JK, Park KH, Park JD, Ghezzi F, Kim BI 1997 Amniotic fluid cytokines (interleukin-6, tumor necrosis factor-alpha, interleukin-1 beta, and interleukin-8) and the risk for the development of bronchopulmonary dysplasia. Am J Obstet Gynecol 177:825-830

5. Rindfleisch MS, Hasday JD, Taciak V, Broderick K, Viscardi RM 1996 Potential role of interleukin-1 in the development of bronchopulmonary dysplasia. J Interferon Cytokine Res 16:365-373

6. Lappalainen U, Whitsett JA, Wert SE, Tichelaar JW, Bry K 2005 Interleukin-1beta causes pulmonary inflammation, emphysema, and airway remodeling in the adult murine lung. Am J Respir Cell Mol Biol 32:311-318

7. Bry K, Whitsett JA, Lappalainen U 2007 IL-1beta disrupts postnatal lung morphogenesis in the mouse. Am J Respir Cell Mol Biol 36:32-42

8. Sisson TH, Hansen JM, Shah M, Hanson KE, Du M, Ling T, Simon RH, Christensen PJ 2006 Expression of the reverse tetracycline-transactivator gene causes emphysema-like changes in mice. Am J Respir Cell Mol Biol 34:552-560 
9. Bäckström E, Lappalainen U, Bry K 2010 Maternal IL-1beta production prevents lung injury in a mouse model of bronchopulmonary dysplasia. Am J Respir Cell Mol Biol 42:149-160

10. Hogmalm A, Sheppard D, Lappalainen U, Bry K 2010 beta6 Integrin subunit deficiency alleviates lung injury in a mouse model of bronchopulmonary dysplasia. Am J Respir Cell Mol Biol 43:88-98

11. Lukkarinen HP, Laine J, Kaapa PO 2003 Lung epithelial cells undergo apoptosis in neonatal respiratory distress syndrome. Pediatr Res 53:254-259

12. Kotecha S 2000 Lung growth: implications for the newborn infant. Arch Dis Child Fetal Neonatal Ed 82:F69-F74

13. Ashour K, Shan L, Lee JH, Schlicher W, Wada K, Wada E, Sunday ME 2006 Bombesin inhibits alveolarization and promotes pulmonary fibrosis in newborn mice. Am J Respir Crit Care Med 173:1377-1385

14. Moss TJ, Newnham JP, Willett KE, Kramer BW, Jobe AH, Ikegami M 2002 Early gestational intra-amniotic endotoxin: lung function, surfactant, and morphometry. Am J Respir Crit Care Med 165:805-811

15. Merritt TA, Cochrane CG, Holcomb K, Bohl B, Hallman M, Strayer D, Edwards DK 3rd, Gluck L 1983 Elastase and alpha 1-proteinase inhibitor activity in tracheal aspirates during respiratory distress syndrome. Role of inflammation in the pathogenesis of bronchopulmonary dysplasia. J Clin Invest 72:656-666

16. Baier RJ, Loggins J, Kruger TE 2001 Monocyte chemoattractant protein-1 and interleukin-8 are increased in bronchopulmonary dysplasia: relation to isolation of Ureaplasma urealyticum. J Investig Med 49:362-369

17. Kotecha S, Chan B, Azam N, Silverman M, Shaw RJ 1995 Increase in interleukin-8 and soluble intercellular adhesion molecule-1 in bronchoalveolar lavage fluid from premature infants who develop chronic lung disease. Arch Dis Child Fetal Neonatal Ed 72:F90-F96

18. Bancalari E, Gonzalez A 2000 Clinical course and lung function abnormalities during development of chronic lung disease. In: Bland RD, Coalson JJ (eds) Chronic Lung Disease in Early Infancy. Marcel Dekker, Inc., New York, pp 41-64

19. Cai Y, Kumar RK, Zhou J, Foster PS, Webb DC 2009 Ym1/2 promotes Th2 cytokine expression by inhibiting 12/15(S)-lipoxygenase: identification of a novel pathway for regulating allergic inflammation. J Immunol 182:5393-5399

20. Létuvé S, Kozhich A, Arouche N, Grandsaigne M, Reed J, Dombret MC, Kiener PA, Aubier M, Coyle AJ, Pretolani M 2008 YKL-40 is elevated in patients with chronic obstructive pulmonary disease and activates alveolar macrophages. J Immunol 181:5167-5173

21. Chupp GL, Lee CG, Jarjour N, Shim YM, Holm CT, He S, Dziura JD, Reed J, Coyle AJ, Kiener P, Cullen M, Grandsaigne M, Dombret MC, Aubier M, Pretolani M, Elias JA 2007 A chitinase-like protein in the lung and circulation of patients with severe asthma. N Engl J Med 357:2016-2027

22. Ober C, Tan Z, Sun Y, Possick JD, Pan L, Nicolae R, Radford S, Parry RR, Heinzmann A, Deichmann KA, Lester LA, Gern JE, Lemanske RF Jr, Nicolae DL, Elias JA, Chupp GL 2008 Effect of variation in CHI3L1 on serum YKL-40 level, risk of asthma, and lung function. N Engl J Med 358:1682-1691

23. Okumura S, Sagara H, Fukuda T, Saito H, Okayama Y 2005 FcepsilonRI-mediated amphiregulin production by human mast cells increases mucin gene expression in epithelial cells. J Allergy Clin Immunol 115:272-279 